\title{
A functional profile of Left Dislocation in Biblical Hebrew
}

\section{Josh Westbury}

Department of Ancient Languages, Stellenbosch University, South Africa | Faithlife Corporation (Logos Bible Software), USA

E-mail: joshwestbury@gmail.com

\begin{abstract}
The primary aim of this paper is to provide a functional profile of verbal Left Dislocation (=LD) constructions in the Torah and Former Prophets (Genesis-2Kings). As a precursor, however, an abbreviated syntactico-semantic description of LD constructions within the aforementioned corpus is provided. This description consists of seven overlapping constructional schemas (i.e. construction types) that form a radial network around a typologically prototypical schema. Accordingly, each schematic type is more or less prototypical depending on its family resemblance (i.e. shared attributes) to the prototype. In light of this formal profile, and of the fact that grammatical constructions are equal parts form and function, the remainder and central focus of the paper will entail a detailed functional explanation of LD. This functional profile will consist of two complementary parts: 1) the central factors motivating the use of LD, and 2) the prototypical and non-prototypical discourse-pragmatic functions achieved by the construction in discourse. Together with the formal description, this functional explanation reveals a textured profile of the LD category, one that consists of a unified radial network of overlapping constructional types.
\end{abstract}

Keywords: Left Dislocation, Information Structure, Discourse Pragmatics, Biblical Hebrew

\section{Introduction}

Despite several studies ${ }^{1}$ on the so-called Left-Dislocation (=LD) construction in Biblical Hebrew $(=\mathrm{BH})$, linguists have failed to reach a consensus with respect to the construction's syntactic, semantic or discourse-pragmatic profile. As a result, a fresh investigation was undertaken (cf. Westbury 2014) with the intent of advancing a more unified explanation of verbal LD constructions in BH. Drawing on recent typological and theoretical research on the syntactic, semantic, and discourse-pragmatic attributes of LD constructions across languages, a set of criteria was developed for the identification and classification of LD constructions in $\mathrm{BH} .{ }^{2}$ These criteria were then applied to the corpus of Gen-2 Kngs, where over 650 instances

\footnotetext{
${ }^{1}$ Cf. Gross (1987), Khan (1988), Naudé (1999), Holmstedt (2014).

${ }^{2}$ Cf. Westbury (2014) and Westbury (2016) for further discussion with respect to the typological and theoretical research.
} 
of LD were identified. ${ }^{3}$ Further analysis revealed that these tokens reflect an abstract network of approximately seven overlapping constructional schemas (i.e. construction types) ${ }^{4}$ where each schema is distinguished based on the clustering together of syntactico-semantic attributes and/or discourse-pragmatic functions. ${ }^{5}$ Moreover, these attributes and functions expose the degree to which each schema is related to a typologically prototypical LD schema. In other words, each constructional schema is determined to be more or less prototypical depending on its respective degree of family resemblance (i.e. shared syntactico-semantic and discourse pragmatic attributes) to the prototypical schema. ${ }^{6}$ In short, this analysis reveals a textured profile of the LD category in $\mathrm{BH}$, one that consists of a unified radial network of overlapping constructional schemas.

The focus of the present paper concerns the functional profile of verbal LD constructions in the Torah and Former Prophets. However, as a precursor, I will provide a brief overview of the seven schematic constructions identified in the aforementioned study, giving special attention to their syntactico-semantic attributes. ${ }^{7}$ The remainder of the paper will concern the functional profile of $\mathrm{LD}$ in $\mathrm{BH}$, in which I will discuss both the central factors motivating the use of $\mathrm{LD}$, and the discourse-pragmatic functions achieved by the construction in discourse.

\section{Schematic LD Types}

\subsection{Prototypical LD}

Typological evidence suggests that the prototypical LD schema consists of a constituent, typically a NP, that both precedes and is detached from the core clause with which it is

\footnotetext{
${ }^{3}$ As an initial point of departure, this investigation assumes, in line with a Construction Grammar approach to linguistic analysis, that a grammatical construction consists of a conventional form-function pairing (cf. Hoffman and Trousdale 2013).

${ }^{4}$ A constructional schema is a generalized template that emerges from entrenched patterns of instantiated usage (Evans and Green, 2006: 754). They are achieved by removing points of difference between a variety of instantiations leaving only their common attributes. Although constructional schemas entail syntactic, semantic, and discourse-pragmatic information, from a structural standpoint, they can be thought of as generalized templates consisting of a sequence of ordered slots that may be filled by a variety of words and phrases of differing grammatical categories (Taylor 1995: 198). By contrast, an instantiation of a constructional schema is a lexically specified instance of a more abstract schema. Both constructional schemas and instantiations of schemas coexist in the grammar, the schema being an abstraction that emerges from instantiated usage patterns (Evans and Green 2006: 755).

${ }^{5}$ In full disclosure, the seven schematic construction types identified and discussed below represent a heuristic parsing of the data. In other words, where one draws the boundary lines between different construction types is somewhat arbitrary. The point is to show that the LD category in BH consists of a variety of differing construction types that are related, in varying degrees, to a typologically prototypical schema. In other words, the LD category consists of a cluster of LD schemas that form a radial continuum, where schemas that align with the prototype are located in the center of the category, while schemas that differ from the prototype occur at varying degrees of remoteness from the prototype (cf. Boas 2013).

6 This is in line with Lakoff's (1987: 483-487) proposal that "regards grammar in general as a radial category, in which the schematic and more regular constructions constitute prototypes while more specific and idiosyncratic constructions are located at the periphery and inherit properties from more central instances of constructions" (Boas 2013: 245).

${ }^{7}$ In reality, form and meaning (or function) are inextricably connected such that one cannot be expressed without the other. Thus, the practice of describing a construction's syntactico-semantic profile apart from its functional profile is done for practical reasons bearing in mind that both are intricately linked and interdependent to one another.
} 
associated. ${ }^{8}$ Moreover, the referent of the detached constituent is resumed within the core clause by a co-referential element, typically in the form of either a regular or clitic pronoun, or an epithet. Approximately $20 \%$ of the tokens in the dataset met this description. The syntacticosemantic attributes that comprise the prototypical schema are as follows:

1. A referential constituent both precedes and is dislocated from a core clause with which it is associated.

2. An alternative position for the dislocated constituent exits within the associated core clause.

3. The alternative position is filled by an anaphoric co-referential resumptive element in the form of either a regular or clitic pronominal, or an epithet. In other words, the referents of the dislocate and resumptive element stand in a total identity relation to one another

4. The dislocated constituent is accompanied by a separate intonation contour

Moreover, an example of the prototype is found in Gen. 2:17:

Gen. $2 \cdot 17^{9}$

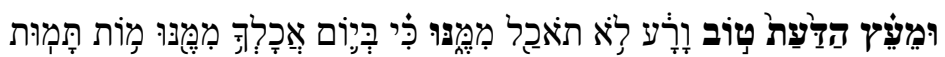

["From the tree of the knowledge of good and evil]i, you shall not eat from iti, for on the day you eat from it, you shall surely die”

\section{$2.2 \quad$ Non-resumptive LD}

The Non-resumptive LD schema constitutes approximately $7 \%$ of the dataset. As the name suggests, this schema is distinguished from the prototype by the lack of an overt co-referential resumptive. Nevertheless, constructions of this type qualify as LD due to the fact that the front most constituent is, to some degree, dislocated from the core clause. This dislocated status is confirmed by either the lack of an available valency slot for the dislocate, or the dislocate's position preceding a grammatical clause boundary marker, such as a conjunction 1 (or wayyiqtol), among others. ${ }^{10}$

\footnotetext{
${ }^{8}$ Cf. Lambrecht (2001:1050), Givón (2001: 235ff), Lopez (forthcoming), inter alia.

${ }^{9}$ Further examples of prototypical LD include: Gen. 2.17; 3.3; 3.12; 4.4; 4.22; 13.15; 15.4; 17.14; 17.17; 19.38; 21.13; 22.24; 23.11; 24.7; 24.14; 25.10; 26.15; 28.13; 28.22; 35.12; 44.17; 47.21; 49.19; 50.5; Exod. 1.22; 9.19; 12.15; 12.16; 12.19; 12.44; 15.15; 19.18; 26.12; 31.14; 32.1; 35.29; Lev. 3.9; 7.7; 7.8; 7.9; 7.19; 7.20; 7.25; 7.27; 7.30; 7.33; 11.3; 11.9; 14.6; 18.29; 20.6; 20.16; 21.3; 22.11b; Num. 4.29; 9.13; 9.17b; 14.31; 14.36-37; 17.3; 18.8; 19.20; 22.20; 22.35; 22.38; 26.33; 33.54; 35.19; 35;30; 35.33; Deut. 1.30; 1.36; 1.38; 2.23; 3.13; 4.3; 12.11; 12.14; 13.1; 14.6; 14.27; 16.6; 17.12; 18.19; 18.20; 20.20; 21.3; 28.61; Josh. 1.3; 11.13; 15.16; 17.3; Judg. 1.12; 5.11; 7.4; 11.24 (2x); 18.30; 1 Sam. 9.20; 13.2; 15.9; 17.37; 18.17; 20.8; 2 Sam. 6.21; 6.22; 6.23; 13.32; 13.33; 14.19; 15.30; 22.41; 1 Kng. 5.19; 6.7; 6.32; 8.19; 9.20-21; 12.17; 13.33; 15.13; 22.14; 2 Kng. 1.4; 1.6; 1.16; 10.29; 13.19; 17.36; 22.18; 23.15; 25.22. Although rare, it is possible for prototypical LD constructions to occur syntactically embedded in a larger clause. For example, see Deut. 4.3 where the entire LD construction is embedded as a complement clause introduced with the complementizer כִ̣.

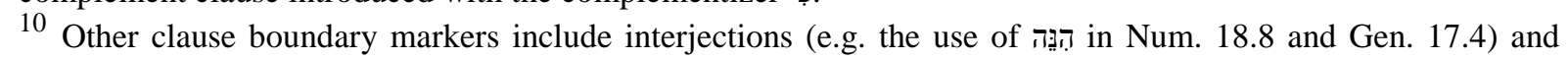
vocative expressions (e.g.1 Kngs. 1.20). Also, conditional/temporal כִִ̣ often functions as a clause boundary marker (e.g. Num. 5.6; Lev. 22.14).
} 
Despite the lack of an overt co-referential resumptive, the dislocate in the Non-resumptive LD schema is often semantically or pragmatically related to another intra-clausal element, or to the clause as a whole. These semantic/pragmatic relations are characterized as: 1) a metonymic identity relation ${ }^{11}$ (as in [2]) a partial identity relation ${ }^{12}$ (as in [3]) a pragmatic relevance relation ${ }^{13}$ (as in [4]) (cf. Tizón-Couto 2012: 38-39, Westbury 2014: 104-105). ${ }^{14}$

\section{Lev. 26.36 Metonymic Relation}

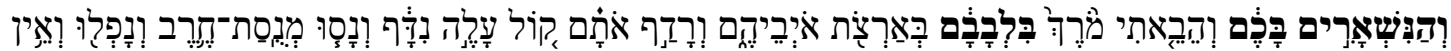

["And as for those of you who are left], I will send faintness into their hearts in the lands of their enemies. The sound of a driven leaf shall put them to flight, and they shall flee as one flees from the sword, and they shall fall when none pursues."

Num. 35.8 Partial Identify Relation

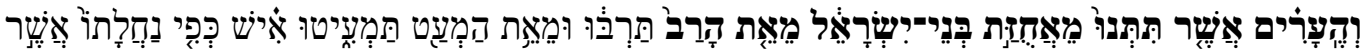

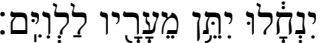

["As for the cities which you shall give from the possession of the Israelites], from the larger tribes you shall take many, and from the smaller tribes, you shall take few; each shall give some of his cities to the Levites in proportion to his possession which he inherits."

$$
\text { Num. 3.46-47 - Relevance Relation }{ }^{15}
$$

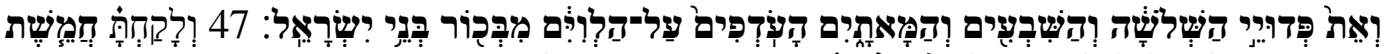

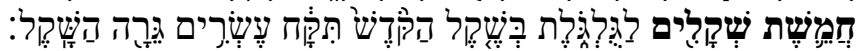

["And as for the price of redemption for the 273 firstborn of the Israelites], 47 You shall take five shekels for each person. You shall collect them according to the standard sanctuary shekel."

\footnotetext{
${ }^{11}$ A metonymic relation is one in which the referent of the dislocated constituent stands in either a hypernemic relation (e.g. whole/part) or hyponymic relation (e.g. part/whole) with another referent of a constituent within the core clause. Often the clause internal element with which the dislocated constituent is metonymically linked takes the form of a NP modified by a possessive determiner. Unlike the prototypical schema, the referent of the determiner is co-indexed with the dislocate, rather than the referent of the NP.

${ }^{12}$ A partial identity relation entails a partial overlap in referents denoted by the dislocated constituent and another clause internal element, respectively.

${ }^{13}$ A relevance relation is one in which a direct semantic link, either metonymic, partial, or otherwise, does not hold between the dislocated constituent and the core clause. The referent of the dislocated constituent in these constructions rather stands in a relevance relation to the ensuing proposition. In other words, the referent of the dislocated constituent functions as a framing device (cf. Fillmore 1982; Croft and Cruse 2004: 7-32) that constrains the interpretation of the following proposition to a certain semantic domain.

${ }^{14}$ Further examples of Non-resumptive LD include: Gen. 9.6; 17.15; 21.12; 34.8; 44.9; Exod. 4.9; 9.6; 9.21; 26.12; 30.33; 30.38; Lev. 11.33; 13.45; 15.18; 20.10; 20.12; 20.13; 25.33; 26.36; Num. 3.46-47; 21.8; 22.11; 23.3; 34.6; 35.8; Deut. 21.3; 28.54; 28.56; Josh. 21.40; Judg. 11.31; 19.301 Sam. 2.10; 3.11; 11.7; 11.11; 20.4; 25.27; 2 Sam. 2.23; 21.5-6; 24.3; 24.17; 1 Kng. 8.41; 11.26; 17.20; 2 Kng. 11.7; 16.14. Moreover, like with the prototype, it is possible for LDs of this type to occur embedded in a larger clause. Cf. 1 Sam. 3.11, and 2 Kings 21.12, note that each subordinate dislocate is headed by the quantifier

${ }^{15}$ Note that in (4)-(5) the dislocated status of the initial constituent is established both by the lack of an available valency slot, as well the position of the dislocate preceding the clause initial conjunctive .
} 
Also included in this schema are constructions that do not possess a semantic or pragmatic relation to another overt clause-internal element. In these constructions, the dislocated status of the initial constituent is confirmed solely on the basis of its position before a grammatical clause boundary marker. In (5), for example, the clause boundary position (i.e. the so-called CPposition) is filled by the interrogative particle מֶֶ. Likewise, in (6), the clause boundary is marked by the conjunction 1 .

$$
\text { 2 Sam. } 24.17^{16}
$$

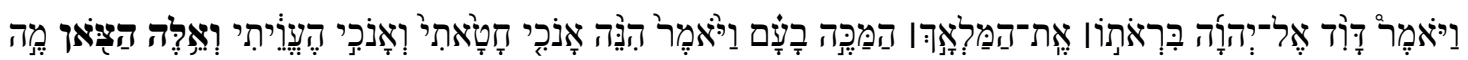

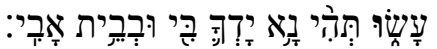
"Then David spoke to Yahweh when he saw the angel who was striking the people, and he said, "Look, I have sinned and I have done wrong, but [these sheep] $]_{i}$ what did theyi do? Please let your hand be against me and against my father's house."

$$
\text { Gen. } 44.9
$$

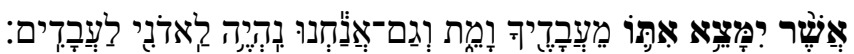
["Whoever is found with it from your servants], he must die, and we also will be my lord's servants."

\subsection{Multiple LD}

In addition to the attributes entailed in both the Prototype and Non-resumptive schemas, the Multiple LD schema involves the dislocation of multiple constituents, or a single constituent comprised of multiple discrete referring expressions. The dislocated constituents of Multiple LD constructions may or may not have a co-referential resumptive element within the matrix clause. When a resumptive is present, the multiple dislocates may be coextensively linked to a single resumptive (typically a pronoun). When a co-referential element is not present, the dislocates may be semantically or pragmatically linked to the associated clause by way of a metonymic, partial, or relevance relation. Tokens instantiating this construction type make up approximately $6 \%$ of the overall dataset. Examples (7) and (8) are representative of this type:

$$
\text { Lev. } 11.42 \text { (single constituent with multiple referring expressions) }{ }^{17}
$$

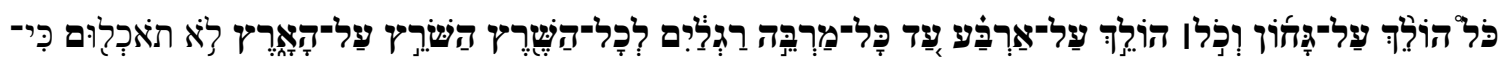

["Whatever crawls on its belly], [whatever goes on all fours], or [whatever has many feet $]_{k}$, [any swarming thing that swarms on the ground], you shall not eat them ${ }_{i j k l}$, for they are detestable."

\footnotetext{
${ }^{16}$ Cf. 2 Sam. 13.13 where the interrogative particle אָנָ is used in a similar way.

17 Dislocates consisting of a single constituent comprised of multiple referring expressions include: Lev. 2.11; 3.3b-4; 3.14-15; 4.8-9; 4.11-12; 7.9; 9.19-20; 11.42; 18.9; 18.10; 21.14; 22.4b-6a; 22.8; 22.22; 22.23; 22.28; 25.44; Num. 4.46-48; 6.7; 31.22-23; 30.10; 30.14; Deut. 1.39; Josh. 13.6; 1 Sam. 14.15; 1 Kng. 8.37-39; 1 Kng. 9.20-21; 2 Kng. 11.5-6; 2 Kng. 24.16; 2 Kng. 25.16.
} 
["But every slave that is bought for money] $]_{i}$ [after you have circumcised him] $]_{j}$, then ${ }_{j}$, he may eat of it."

\subsection{Pronominal LD}

The pronominal LD schema is distinguished by a dislocated pronoun, which may be either strong or weak (i.e. clitic). The dislocated status of the initial pronoun is confirmed by either a clause-internal co-referential pronoun or epithet, and/or a clause boundary marker (e.g. a conjunction r, etc.) at the juncture between the dislocate and the matrix clause. These constructions make up roughly $2 \%$ of the dataset. Furthermore, Pronominal LDs, as we will see below, are always used to accomplish a highly non-prototypical function. As a result, this schema is positioned further still from the prototype. Example (9) is representative of the Pronominal LD schema.

Gen. $24 \cdot 27^{19}$

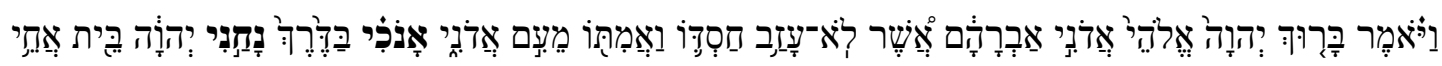

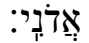

"And he said, 'Blessed be Yahweh, the God of my master Abraham, who has not forsaken his steadfast love and his faithfulness toward my master. [As for me]i, Yahweh has led mei in the way to the house of my master's relatives."

While all constructional schemas consist of generalized features by definition, cognitive linguists and construction grammarians have long observed that constructions tend to occur on a continuum between those that are more schematic (e.g. abstract) and those that are more substantive (cf. Croft and Cruse, 2004:225-247, Goldberg, 2013:15-31). More schematic constructions consist of abstracted generalized templates where sequential open slots may be filled by a variety of different words or phrases (cf. Taylor, 1995:198). By contrast, constructions that are more substantive entail fixed components that occur in the same slot in every instance. The Prototypical, Non-resumptive, and Pronominal schemas described above are all fairly schematic. ${ }^{20}$ However, the final three schemas that emerged from the data are more substantive, with each construction type possessing one or more fixed elements. Moreover, as we will see at the end of this paper, these "substantive schemas" have also conventionalized various aspects of their functional profile to the degree they have become virtually formulaic in their interpretation.

\footnotetext{
18 Dislocates with multiple constituents include: Lev. 22.3; Num. 14.24; 1 Sam. 2.13; 14.19; 17.24.

${ }^{19}$ Further examples include: Gen. 6.21; 24.7; 48.7; Lev. 17:3-4; 17:8-9; 17.10; Num. 5.10 (2x); 18.8; Deut. 18.14; Josh. 23.9; Judg. 5.3; 2 Sam. 13.13.

20 Strictly speaking, since instantiations of the Pronominal LD schema always exhibit a dislocated pronoun, the Pronominal schema is considered more substantive than both the Prototype and Non-resumptive schemas.
} 


\subsection{Anaphoric}

The first substantive construction is characterized by a dislocated PP or NP (rare) and is coindexed to an anaphoric adverbial

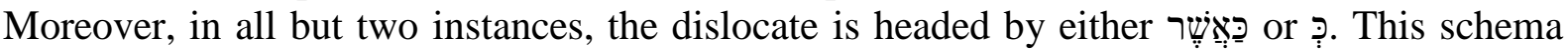
comprises approximately $7 \%$ of the dataset, and is represented by example (10) below.

$$
\text { 2 Sam. } 9.11^{21}
$$

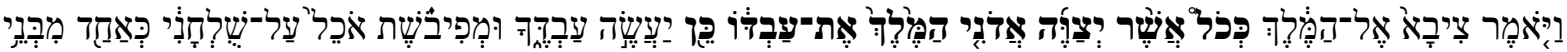

"Then Ziba said to the king, ['According to all that my lord the king commands his servant]i, soi your servant will do.' So Mephibosheth ate at David's table as one of the king's sons."

\subsection{Conditional LD}

A second substantive LD schema consists of those constructions that contribute to the formulation of a conditional clause. These constructions are characterized by a dislocated NP or indefinite pronoun that precedes the protasis of a conditional clause. The dislocated status of the initial constituent is confirmed by כִ כor more rarely or marking the beginning of the protasis clause. The dislocate may or may not be semantically linked to a correlative overt element in the protasis or apodosis of the conditional clause. Furthermore, in virtually every instance, tokens of this type occur in legal contexts as casuistic precepts. Conditional LDs make up approximately 5\% of the dataset. Example (11) represents the Conditional LD schema.

$$
\text { Num. } 5.6^{22}
$$

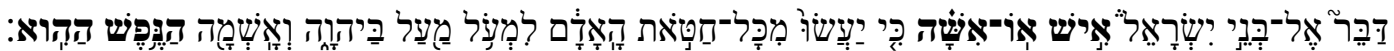
"Speak to the Israelites and say, ["A man or a woman]i, if they commit any of the sins that people commit by breaking faith with Yahweh, that personi is guilty."

\section{$2.7 \quad$ Temporal LD}

The final substantive schema consists of constructions with a dislocated temporal deictic clause or phrase. The dislocated status of the initial temporal expression is determined by a clause boundary marker (typically i or wayyiqtol), or less often, by an overt co-referential resumptive element. Within the network of schematic types that make up the LD category in BH, temporal LDs are located furthest from the prototype. This is due in part to the fact that, unlike the above described schemas, the dislocates of temporal LDs do not refer to participants (specific or generic) or entities/objects. Rather, the dislocates of Temporal LDs refer deictically to temporal parameters under which the following proposition (or discourse unit) should be interpreted.

\footnotetext{
21 Further examples include: Gen. 6.22; Exod. 7.6; 12.28; 12.50; 25.9; 27.8; 39.32; 39.42; 39.43; 40.16; Num. 2.17; 2.34; 5.4; 8.4; 8.20; 8.22; 9.5; 9.14; 9.17a; 15.12; 15.14; 15.20; 17.26; 32.31; 36.10; Deut. 7.19; 8.20; 12.22; Josh. 1.17; 10.39; 11.15; 14.5; 23.15; Judg. 1.7; 15.11; 1 Sam. 9.13; 11.7; 2 Sam. 7.17; 9.11; 13.35; $16.19 ; 1$ Kng. 1.30; 1.37; 2.38; 2 Kng. 16.11; 22.18.

22 Further examples include: Lev. 1.2; 2.1; 4.2; 5.4; 5.15; 5.21; 7.21; 12.2; 13.2; 13.18; 13.24; 13.29; 15.16; 15.19; $15.25 ; 19.20 ; 20.27 ; 22.12 ; 22.13 ; 22.14 ; 22.21 ; 22.27$; Num. 5.6; 5.12-15; 5.20; 6.2; 9.10; 27.8; 30.3; 30.4; 1 Kng. 8.37-39; 9.4.
} 
Despite its remote position relative to the prototypical schema, instantiations of the Temporal LD schema represent approximately 53\% of the overall dataset. A representative example of the Temporal schema is found in 2 Sam. 11.16.

$$
\text { 2 Sam. } 11.16^{23}
$$

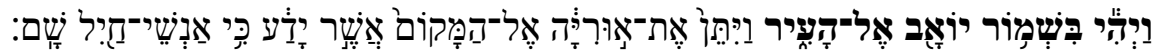

["And as Joab was besieging the city], he assigned Uriah to the place where he knew there were valiant men."

This syntactico-semantic profile of the seven LD schemas described above can be explained both in terms of the cognitive-pragmatic motivations for the use of LD in discourse, and the overarching pragmatic functions achieved by the construction in context. Addressing each of these issues in turn, we will begin by proposing a hypothesis for the motivating constraints determining the use of $\mathrm{LD}$ in $\mathrm{BH}$, followed by a description of the measures used to evaluate this hypothesis, along with the results of this evaluation.

Furthermore, the cognitive motivations identified will provide the basis for explaining the communicative goals and pragmatic effects achieved by the use of LD in particular contexts. As with the syntactico-semantic profile sketched above, the functional profile of LD also reflects prototypically effects. Discourse-pragmatic functions are construed as either more or less prototypical depending on the degree to which they overlap with a prototypical function.

\section{Cognitive Motivation}

It is hypothesized that the central constraint motivating the use of LD in $\mathrm{BH}$ concerns the low degree of cognitive accessibility entertained by a referent at the point in which it is expressed in the discourse. In other words, the use of LD is prototypically triggered by the need to say something about a referent which the writer assumes is identifiable, but only minimally

\footnotetext{
23 Further examples include: Gen. 3.5; 4.3; 4.8; 6.1; 7.10; 8.6; 11.2; 12.11; 12.12; 19.15; 19.29; 19.34; 20.13; 21.22; 22.1; 22.4; 22.20; 24.20; 24.22; 24.30; 24.45; 24.52; 25.10; 25.11; 26.8; 26.32; 26.34; 27.1; 27.30; 27.34; 27.40; 29.10; 29.13; 29.23; 30.41; 31.10; 31.37; 32.18; 34.25; 35.16; 35.17; 35.18; 35.22; 37.18; 37.23; 38.1; 38.9; 38.24; 38.38; 38.29; 39.7; 39.10; 39.11; 39.13; 39.15; 39.18; 39.19; 41.8; 43.2; 43.21; 44.3; 44.24; 44.31; 46.33; 47.24; 48.1; 50.5; Exod. 1.16; 1.19; 2.11; 2.23; 4.21; 4.24; 6.28-29; 12.3; 12.25; 12.26; 12.29; 13.5; 13.11; 13.14; 13.15; 13.17; 15.19; 16.5; 16.7; 16.10; 17.4; 17.11 (2x); 18.13; 19.1; 19.16; 30.12; 32.19; 32.30; 32.34; 33.22; Lev. 22.3; Num. 7.1; 7.89; 9.17 (2x); 9.19; 10.9; 10.10; 10.35; 11.25; 15.2; 15.8; 15.14; 15.18; 16.31; 17.7; 17.32; 18.26; 18.30; 22.41; 25.19; 35.10; 35.51; Deut. 2.16; 4.30; 5.23; 6.10-11; 6.20; 7.1-2; 9.9-10; 9.23; 11.29; 12.11; $12.14 ; 15.16 ; 16.6 ; 17.18 ; 20.2 ; 20.9 ; 20.10 ; 21.10-11 ; 22.8 ; 23.10 ; 23.14 ; 23.25 ; 23.26 ; 24.1 ; 25.1 ; 26.1 ; 26.12$; 27.2; 29.18; 30.1-2; 31.20; 31.24-25; Josh. $1.1 ; 2.5 ; 2.14 ; 3.2 ; 3.3 ; 3.14 ; 3.15 ; 4.1 ; 4.11 ; 4.18 ; 5.1 ; 5.8 ; 5.13 ; 6.15$; 6.20; 8.5; 8.14; 8.24; 9.1-2; 9.16; 10.1-2; 10.11; 10.20; 11.1; 15.18; 17.13; 22.7; 23.1; 23.16; 24.29; Judg. 1.1; $1.14 ; 1.28 ; 2.18 ; 3.18 ; 3.27 ; 5.11 ; 6.7 ; 6.25 ; 7.9 ; 7.15 ; 8.7 ; 8.33 ; 9.42 ; 11.4 ; 11.16-17 ; 11.26 ;$; $11.35 ; 11.39 ; 12.5-$ $6 ; 13.20 ; 14.11 ; 14.15 ; 14.17 ; 15.1 ; 16.1 ; 16.4 ; 16.16 ; 16.25 ; 19.5 ; 21.4 ; 21.22 ; 1$ Sam. $1.4 ; 1.20 ; 2.15 ; 4.5 ; 4.18$; 4.20; 5.9; 5.10; 7.2; 8.1; 9.26; 10.2; 10.9; 10.11; 12.8; 13.10; 13.22; 14.1; 14.19; 16.16; 16.23; 17.24; 17.48; 18.6; 18.10; 18.19; 20.27; 20.35; 24.2; 24.6; 24.17; 25.20; 25.30; 25.37; 25.38; 28.1; 30.1; 30.25; 31.8; 2 Sam. 1.1; 1.2; 2.1; 3.6; 4.4; 4.10; 5.24; 6.13; 7.1; 7.4; 7.12; 8.1; 10.1; 10.14; 10.15; 11.1; 11.2; 11.14; 11.16; 11.19; 12.18; 13.1; 13.23; 13.28; 13.36; 15.1; 15.2; 15.5; 15.7; 15.32; 16.16; 17.6; 17.9; 17.21; 17.27; 19.26; 21.18; 1 Kng. 1.14; 1.21 ; 2.39; 3.18; 5.21; 6.1; 8.10; 8.33; 8.35; 9.1; 11.15; 11.29; 12.2; 12.20; 13.4; 13.23; 13.31; 14.6; 14.12; 15.21; 16.18; 17.7; 18.4; 18.17; 18.27; 18.29; 18.36; 18.44; 18.45; 19.13; 20.12; 20.26; 20.29; 20.40; 21.15; 21.16; 21.27; 22.32; 22.33; 2 Kng. 2.1; 2.9; 2.11; 3.5; 3.15; 3.20; 4.6; 4.8; 4.11; 4.18; 4.25; 4.40; 5.7; 5.8; 6.5; 6.20; 6.24; 6.26; 6.30; 7.12; 8.3; 8.15; 9.22; 10.2; 10.7; 10.9; 10.25; 12.11; 13.21; 14.5; 17.21; 19.1; 19.35; 19.37; 22.11; 25.3.
} 
accessible to the addressee. This hypothesis is foremost grounded in Lambrecht's cognitive Principle of the Separation of Reference and Role, a principle which stipulates that it is cognitively too costly, and therefore disadvantageous, to both introduce a referent and talk about it in the same clause. Put differently, without LD, the mental effort required to remember or infer an inaccessible referent would have to be performed simultaneously with another costly processing task: that of interpreting the referent's semantic or pragmatic role within the proposition (Lambrecht, 1994:166). ${ }^{24}$ The partitioned structure of the LD construction mitigates the high processing cost associated with these two cognitive tasks by allowing the hearer/speaker to perform these tasks separately. It follows, therefore, that the LD construction exhibits an iconic syntactic form which reflects an underlying cognitive constraint. ${ }^{25}$

To evaluate the above hypothesis, two complementary measures are applied to the dataset, the results of which provide an accurate estimate of the cognitive status of dislocated referents at their point of use- The first measure concerns the specific form of the dislocated expression. In particular, research by Prince (1981), Gundel et al. (1993), Ariel (1990, 2001), inter alia, suggests that a referent's assumed degree of accessibility often corresponds directly with the type of expression used to refer to it. Simply put, referential expressions function as cognitive “Accessibility Markers”. As a general pattern, a referent's degree of accessibility is inversely proportional to three parameters: 1 ) the degree to which the referent is informative (i.e. the amount of lexical information provided), 2) the referent's rigidity (i.e. the addressee's ability to pick out a unique referent based solely on the form), and 3) the referent's phonologically attenuation (i.e. phonological size) (Ariel 2001: 32). In other words, the more informative, rigid and unattenuated the expression, the lower the degree of accessibility, and vice versa.

This correlation between referential form and cognitive status has been expressed by various models, including Prince's “Familiarity Scale” (1981) and Ariel’s “Accessibility Scale” (1991, 2001). One of the more significant models is that of the Givenness Hierarchy by Gundel et al.

\footnotetext{
24 The PSRR is advantageous for both the speaker and the hearer. "From the speaker's point of view, it is easier to construct a complex sentence if the lexical introduction of a non-active topic referent is done independently of the syntactic expression of the proposition about the referent" (Lambrecht 1994: 185). Moreover, the hearer is cognitively helped by the construction in that "it is easier to decode a message about a topic if the task of assessing the topic referent can be performed independently of the task of interpreting the proposition in which the topic is an argument" (ibid.). Hence, topic referents that are not yet active, and thus cannot be encoded as preferred topic expressions (i.e. pronouns), appear as lexical phrases outside the clauses that express propositional information about them (ibid.: 186).

According to Lambrecht, the PSRR dictates that a theoretical distinction be drawn between the grammatical strategies employed in coding a referent as a topic expression in a sentence (ibid.: 186-187). This distinction results in two types of topic expressions: Reference-oriented, and Role-oriented. Reference-oriented topic expressions merely serve to designate a topic referent, prototypically by means of a nominal phrase, while on the other hand, role-oriented topic expressions designate the topic referent anaphorically or deictically by way of a pronominal expression (ibid.: 186-187). Furthermore, while the semantic role of reference-oriented topic expressions is not discernable from their form or position in a sentence, role-oriented expressions serve as "grammatical links between the topic referent and the proposition by indicating the semantic role of the referent as an argument, i.e. as a participant in the action, event or state expressed by the proposition" (ibid.: 187). With respect to the LD construction in particular, the dislocated constituent prototypically serves to activate the referent about which the following proposition conveys some new information. Lambrecht, therefore, refers to the dislocated constituent as a referent-oriented topic-expression. The resumptive element, in turn, serves as a roleoriented topic expression that satisfies an argument position in the clause proper (ibid.). While the cognitive constraints that constitute the PSRR are universal, their grammatical manifestation in individual languages is subject to typological variation.
}

25 Cf. Westbury (2016) 
(1993), represented in Figure 1. The Givenness Hierarchy is a linear entailment scheme that maps particular referring expressions to corresponding cognitive statuses, such that each status entails every other status to the right on the scale. For example, a referent that is Uniquely Identifiable is also Referential, and Type Identifiable. Accordingly, this model was used as an empirical tool for plotting the accessibility status of dislocated referents in the dataset. ${ }^{26}$

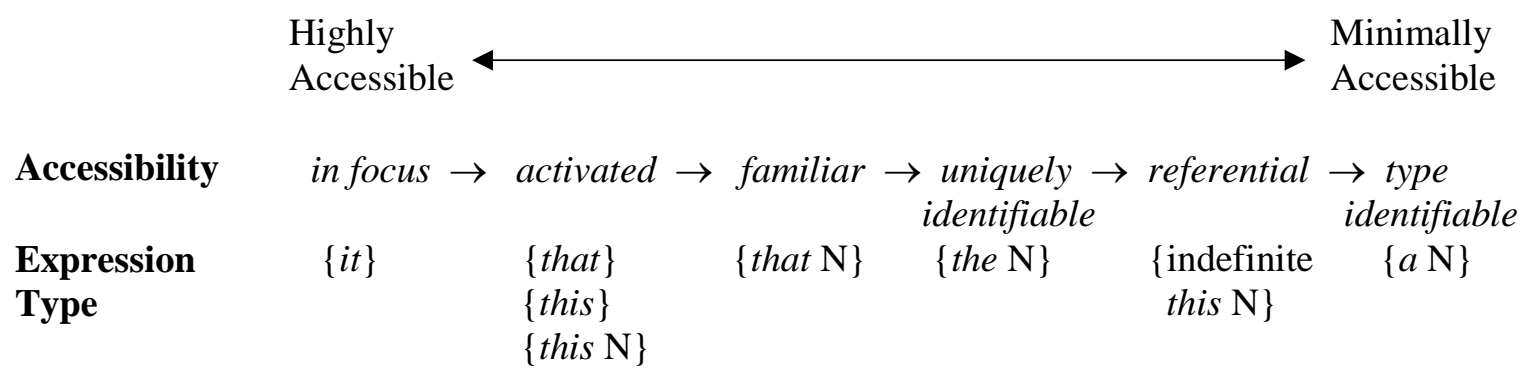

Type Identifiable: The addressee is able to access a representation of the type of object described by the expression.

Referential: $\quad$ The addressee is able to access a representation of the type of object described by the expression.

Uniquely

Identifiable:

The addressee can identify the speaker's intended referent on the basis of the nominal alone.

Familiar:

The addressee can uniquely identify the intended referent on the basis of an existing representation in memory.

Activated: $\quad$ The referent is represented in current short-term memory.

In Focus: $\quad$ The referent is at the current center of attention.

Figure 1: The Givenness Hierarchy ${ }^{27}$

This results of this analysis reveal that approximately $92 \%$ of the dislocated expressions register no higher than Uniquely Identifiable on the Givenness Hierarchy. In other words, the dislocated

\footnotetext{
${ }^{26}$ It is worth noting, however, that although each form-status mapping is represented as a discrete category, the reality is likely much more complex. In particular, Ariel, has argued that the cognitive basis of referential forms should not be thought of as a disjunction of discrete statuses, as per the Givenness Hierarchy, but rather as overlapping spheres of accessibility that exist along a continuum (Ariel 2001: 63). Although this is most certainly more accurate, the Givenness Hierarchy nevertheless functions as a useful tool for estimating the accessibility of referents in discourse. I have therefore adopted the cognitive categories reflected in the Givenness Hierarchy for heuristic purposes, although in light of Ariel's arguments, they are re-conceptualized as non-discrete spheres along a continuum.

${ }^{27}$ The distribution of the dislocates in my dataset on the givenness hierarchy are as follows: focus ( $\left.0 \%\right)$, activated (4\%), familiar (4\%), uniquely identifiable (51\%), referential (26\%), type identifiable (15\%).
} 
expressions are generally highly informative, rigid, and unattenuated, signaling a relatively low degree of cognitive accessibility. ${ }^{28}$

However, these results are potentially obscured by the intentional use of low accessibility markers to encode highly accessible referents, a discourse-pragmatic device referred to as "referential over-encoding." For example, although pronouns are typically used for active referents, or those at the current center of attention, such a referent may instead be encoded by a full lexical expression in order to produce a particular pragmatic implicature. Indeed, this is precisely why the Givenness Hierarchy is formulated in terms of an entailment scheme in which each form-status category entails every other category to its right. For instance, a referent with the cognitive status Activated or In Focus may be encoded by a referring expression typically used for Uniquely Identifiable referents since the former entails the later in the hierarchy. It is therefore necessary to account for false-positives resulting from referential over-encoding when attempting to assess the cognitive accessibility of a referent based solely on the type of referring expression used.

To account for false positives resulting from over-encoding, a second measure examining the source of a given referent's accessibility is applied to the dataset. In particular, discourse referents are made accessible by one of three general sources: First, they may be textually accessible by virtue of having been explicitly mentioned in the prior discourse. Second, they may be situationally accessible by virtue of their presence within the shared text-external context of the interlocutors. Or, third, they may be inferentially accessible by virtue of their implicit relation to either another entity or conceptual frame in the discourse, or their location within the long-term memory of the addressee (e.g. Sun, Moon, etc.). By accounting for the source of accessibility, a more accurate assessment of the referent's cognitive status is obtained, in addition to isolating false positive form-status pairings due to the potential for over-encoding.

This analysis reveals that approximately $25 \%$ of the dislocates analyzed are found to be textually accessible, meaning that the referent had been explicitly introduced or referred to at some previous point in the discourse. Moreover, virtually all of the referents are encoded by expressions registering as Uniquely Identifiable or lower on the Givenness Hierarchy, ostensibly indicating a low degree of accessibility. Yet, despite this use of low accessibility markers, only $20 \%$ of these referents possessed antecedents occurring at distances substantially greater than 15 clauses, while $80 \%$, have antecedents at a relatively close proximity, within 15 clauses. This suggests that the majority of textually accessible referents represent instances of over-encoding, a point that will prove significant in explaining the discourse function of LD in BH below.

In addition to textually accessible dislocates, approximately $2 \%$ were found to be situationally accessible by virtue of their presence in the text-external context. In virtually every instance, the referent was one of the speech participants, and was therefore presumed to be highly accessible, or even active. As a result, situationally accessible referents are predominately encoded as pronouns, an accessibility marker reserved for active referents. ${ }^{29}$

\footnotetext{
${ }^{28}$ For further discussion of this analysis, along with examples and percentages for each category, see Westbury (2014: 286-293).

${ }^{29}$ By contrast, the dislocate in 1 Sam. 25.27 is a situationally accessible inanimate object and arguably entertains a low degree of accessibility. For further discussion of this case, see Westbury (2014: 304).
} 
Finally, approximately $73 \%$ of the dislocates were found to be accessible by virtue of an inference relation prompted by one or more contextual factors. An overwhelming majority of these (83\%) were determined to be inferable based on their membership in a so-called Partially Ordered Set Relation, while some (6\%) were inferential via a conceptual frame/script (6\%), or via an anchoring relation (4\%). Lastly, a remaining (7\%) were inferentially accessible as a result of their inherent saliency as part the general knowledge of the universe, that is knowledge pertaining to the natural, social, and cultural universe shared by the writer and addressees. For instance, some referents in BH narrative (e.g. Moses, Abraham, Sun, Moon, etc.) are assumed to be accessible due to their salient position within the long-term memory store of the reader. ${ }^{30}$ While it is difficult to specify the precise degree of accessibility of inferred referents, it is reasonable to assume that they entertain lower degrees of accessibility than entities explicitly mentioned in the preceding discourse (textual) or referents that are accessible from the textexternal context (situational). This assumption is supported by the tendency for inferred entities to possess looser cohesive links to their triggers, therefore ostensibly demanding a greater degree of processing cost to activate them. For instance, inferred referents require the addressee to accomplish two separate cognitive tasks simultaneously: that of identifying or creating a cognitive representation, and that of accessing that representation. ${ }^{31}$

The results of measure described above are summarized in Figure 2, below:

\begin{tabular}{|l|l|}
\hline 1. Textual: & $\begin{array}{c}\text { The referent has been explicitly mentioned in the prior discourse. } \\
25 \% \text { (Accessibility Marker } \leq \text { Uniquely Identifiable) } \\
80 \% \text { Over-encoded (antecedent }<15 \text { clauses) } \\
20 \% \text { Low Accessibility (antecedent }>15 \text { clauses) }\end{array}$ \\
\hline 2. Situational: & $\begin{array}{l}\text { The referent exists within the text-external context shared by the } \\
\text { interlocutors. } \\
2 \% \text { (Accessibility Marker } \leq \text { Uniquely Identifiable) }\end{array}$ \\
\hline
\end{tabular}

\footnotetext{
${ }^{30}$ It is important to keep in mind that ancient BH narratives recount the lives of famous and infamous men and women of Israel's past, in addition to famous locations and artifacts of Israel's heritage. These figures, places and artifacts are often assumed by the writers to be identifiable due to the universe of discourse shared by the writer and reader, or that there existed only one notable referent which could be denoted by these NPs, e.g. Abraham, Moses, David etc. The reader is assumed to know these unique referents and therefore they need not be introduced every time they appear in a new story. Rather, they are considered inactive referents stored in the long-term memory of the reader (Heimerdinger 1999: 133-134).

${ }^{31}$ It is conceivable, as Ariel (2001: 33) points out, that some inferred referents may entertain higher degrees of accessibility than some textually accessible referents, depending on the context. This is perhaps most likely with referents that are a permanent fixture of the natural, social, or cultural universe. Nevertheless, inferentially identifiable/accessible entities, on average, entertain a relatively low degree of accessibility as compared to other recently mentioned referents, or those immediately accessible from the text-external context. Furthermore, their low degree of identifiability/accessibility is substantiated by the types of expressions (i.e. accessibility markers) used to encode these referents. In virtually every instance, the inferentially accessible referents are encoded by accessibility markers that rank no higher than Uniquely Identifiable on the Givenness Hierarchy.

32 Moreover, these referents were often separated from their antecedent by one or more discourse boundaries (e.g. chapter breaks, paragraph breaks, or even book boundaries).
} 


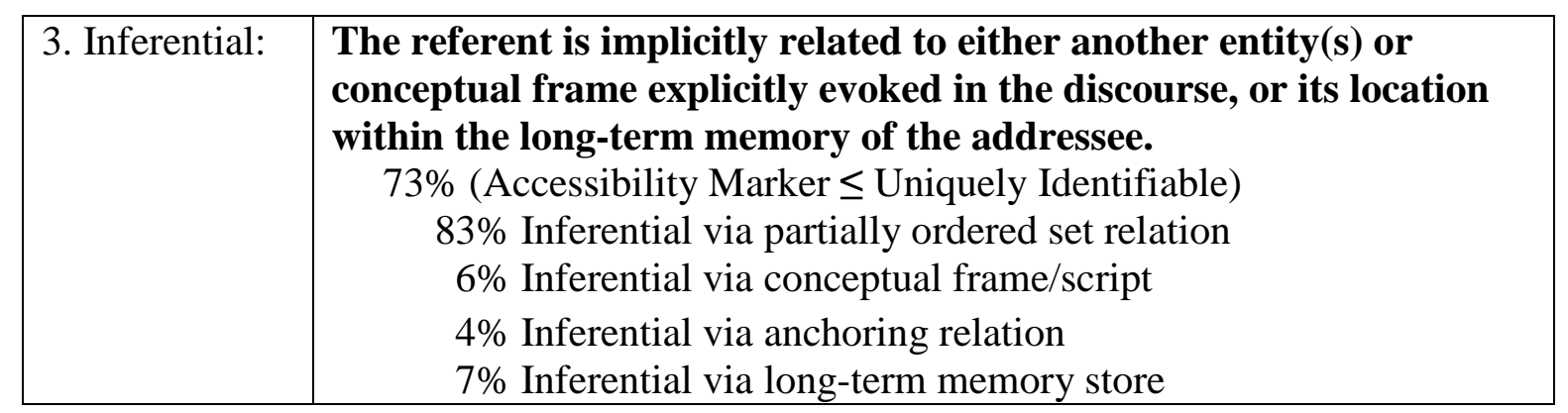

Figure 2: Source of Accessibility

In short, these two measures-the type of referring expression used and the source of referent's accessibility-suggest that the dislocates in the dataset generally entertain low degrees of accessibility. This evidence supports the aforementioned hypothesis, that the use of LD in BH is iconically motivated by the need to talk about a referent which the writer assumes is identifiable, but only minimally accessible to the addressee. Moreover, this constraint provides the key point of departure for discussing the overall communicative goals and pragmatic effects achieved by the construction in $\mathrm{BH}$ discourse.

\section{Discourse Function}

\subsection{The Core Function of LD: (Re)Activation of Minimally Accessible Referents}

In light of the constraint on accessibility just outlined, I proposed that, at its most basic level, $\mathrm{LD}$ in $\mathrm{BH}$ is a discursive strategy used to (re)activate referents or propositions which are assumed to entertain a low degree of accessibility in the mind of the addressee. This function is motivated by the iconic form of the LD construction which, as stated above, entails a uniquely partitioned structure which facilitates the processing of two cognitively costly tasks: that of activating a minimally accessible referent and interpreting that referent's role within the proposition.

While its core discursive function is that of (re)activation, LD constructions that accomplish this function also fall into one of three sentence-level pragmatic categories. These are: Topic Announcing LD, Focus Announcing LD, and Framing LD. To which category a particular token belongs depends on the resumptive or otherwise semantically linked element's pragmatic relation to the proposition. I will discuss each of these categories in turn.

\subsubsection{Topic Announcing}

A topic Announcing LD construction is one in which the newly (re)activated referent fulfills a topic relation within the associated proposition. Research shows that sentences with active topic referents are easier to process (cf. Lambrecht 1994: 165, Givón 1983: 17; inter alia). As a result, writers employ LD constructions in order to (re)activate an inactive referent with a low degrees of accessibility, thereby ratifying the referent as an acceptable topic for the associated proposition. Moreover, the (re)activation + topic announcing function is widely held to be the 
typologically prototypical function for $\mathrm{LD}$, and therefore serves as the exemplar function for this analysis. ${ }^{33}$

Furthermore, Topic Announcing LDs may involve either primary or secondary topic relations. Primary topics usually coincide with the syntactic subject, while secondary topics tend to coincide with the direct object. The examples in (13) and (14) illustrate each of these types.

$$
\text { Deut. } 17.12 \text { (Primary Topic) }^{34}
$$

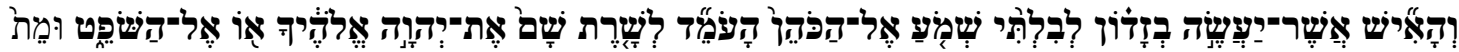

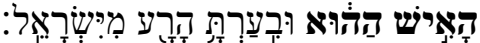
["The person who who acts arrogantly, refusing to listen either to the priest who stands there serving Yahweh your God, or the judge $]_{i}$, that mani must die. You shall purge the evil from Israel."

In Deut. 17.8-13, Moses provides instruction for the Israelites for resolving insoluble legal cases. In v.12, the Israelites are told what will happen on the occasion one of them contemptuously refuses to comply with the ruling. To communicate this, the writer activates an inferentially accessible referent by way of LD. The complexity of the dislocated NP (def.N + restrictive relative) results from the referent's low degree of accessibility. The use of LD separates the task of activation from that of interpreting the referent's role in the proposition, thereby mitigating the processing effort required by the hearer or reader. Moreover, by (re)activating the referent by way of dislocation, the referent becomes a more acceptable topic for the ensuing proposition. In this case the topic expression is realized by the co-referential demonstrative phrase הָאִיש הַהוּא within the core clause.

Moreover, in example (14), from 1 Sam. 9.20, the referent of the complex dislocated NP is remotely accessible from its earlier mention in v.5. Therefore, the LD construction is used to (re)activate and thereby ratify a referent to function as the secondary topic in the associated proposition. As with their primary counterparts, secondary topics must be given, or

\footnotetext{
${ }^{33}$ To clarify, it is the clause-internal resumptive element that serves as the topic expression and not the dislocated constituent. The dislocated constituent cannot, strictly speaking, function as the topic expression since it is syntactically detached from the clause which encodes the pragmatically structured proposition. Since the topic relation only exists relative to a proposition, it follows that the topic expression must occupy a position within the syntactic dependency relations of the clause. Thus, while the dislocated constituent fulfills a (re)activation function, the topic relation is satisfied by the co-referential resumptive or otherwise semantically linked element within the clause. Lambrecht also recognizes the inherent contradiction in referring to the dislocated constituent as "Topic Phrase." He writes: "Since a detached lexical topic constituent does not occupy an argument position in a clause, it is strictly speaking not with the lexical topic NP but with the anaphoric pronominal topic expression that the pragmatic aboutness relation [i.e. topic, JRW] between the referent and the proposition is expressed. It is therefore slightly inconsistent to call such a detached lexical constituent a 'topic NP'. Rather it is a 'topicannouncing' NP" (Lambrecht 1994.: 188).

${ }^{34}$ Further examples include: Gen. 4.4; 4.22; 9.6; 17.14; 22.24; 24.7; 34.8; 44.9; Exod. 4.9; 9.6; 9.21; 12.15; 12.19; 19.18; 26.12; 30.33; 30.38; 31.14; 25.29; Lev. 7.20; 7.25; 7.27; 13.45; 18.10; 18.29; 20.10; 20.12; 20.13; 22.4b6a; 25.32; 25.44; Num. 4.46-48; 9.13; 14.36-37; 19.20; 21.8; 22.11; 30.10; 34.6; 35.30; Deut. 1.30; 3.13; 17.12; 18.20; 21.3; 28.54; 28.56; Josh. 17.3; 21.40; Judg. 11.31; 18.30; 19.30; 1 Sam. 2.13; 3.11; 11.11; 17.37; 25.27; 2 Sam. 2.23; 15.30; 21.5-6; 24.3; 24.17; 6.23;1 Kng. 6.7; 8.41; 11.26; 2 Kng. 11.5-6; 11.7; 25.16; 11.7.
} 
presupposed information. Unlike primary topics, however, secondary topics exist as integral parts of the focus structure of the proposition. ${ }^{35}$

1 Sam. 9.20 (Secondary Topic) $)^{36}$

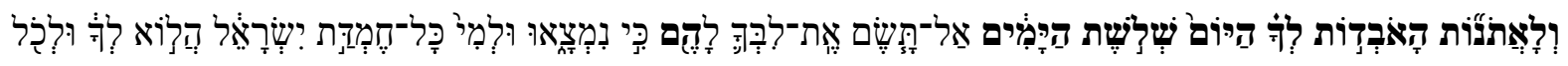

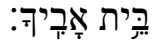

["As for your donkeys that were lost three days ago]i, give no further thought to them because they have been found. And who does all Israel desire but you and all your father's family?"

\subsubsection{Focus Announcing}

It addition to topics, the dislocated constituent also frequently announces the focus of the following proposition. That is to say that the resumptive element satisfies a focal relation to the proposition, rather than a topical one. Although not uncommon in BH, Focus Announcing LDs represent a less prototypical discourse function than that of topic-announcing LDs. ${ }^{37}$ Nevertheless, Focus Announcing constructions are also motivated by the PSRR. Rather than ratifying a topic referent, however, Focus Announcing LD mitigates the processing cost associated with activating a referent and interpreting that referent's role within the propositional assertion.

Furthermore, Lambrecht and others have shown that, across languages, focal constituents often carry a prosodic accent (1994: 218ff). Along these lines, Khan has proposed an additional motivating constraint for the use of Focus Announcing LDs. When the focal constituent is long it prohibits a speaker/writer from evenly distributing the stressed accent over the constituent (Khan 1988: 94). Thus, an LD construction is employed so that the shorter resumptive expression can carry the accent by proxy. Consider the example from Deut. 20.20 in (15) below: ${ }^{38}$

Deut. $20.20^{39}$

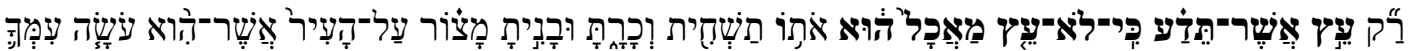

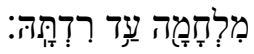

["Only the trees that you know are not used for food] , them $_{i}$ you may destroy and cut so that you may build siege works against the city that is waging war against you, until it falls."

\footnotetext{
${ }^{35}$ For further discussion on the function of secondary topics, see Nicolaeva (2001), Dalrymple and Nicolaeva (2014), and Westbury (2014: 80ff).

${ }^{36}$ Further examples include: Gen. 2.17; 3.3; 26.15; 28.13; 28.22; 30.3; 35.12; 49.19; Exod. 1.22; 15.15; Lev. 2.11; 3.9; 4.11-12; 7.19; 7.30; 9.19-20; 18.9; 20.6; 20.16; 22.22; 22.23; 26.36; Num. 4.29; 14.27; 14.31; 26.33; Deut. 2.23; 14.27; 18.19; 28.61; Josh. 15.16; 2 Sam. 14.10; Judg. 1.12. 1 Kng. 6.32; 12.17; 2 Kng. 25.22.

${ }^{37}$ Cf. Andrason’s observations regarding Arabic (2016a), and Polish (2016b).

38 This relates to Andrason's observation concerning the relevance pertaining to the length of the resumptive entity in Arabic (2016a), and Polish (2016b).

${ }^{39}$ Further examples include: Gen. 3.12; 13.15, 15.4; 23.11, 24.14; 44.17, 50.5; Exod. 12.16; Lev. 7.7; 7.8; 7.33; 11.3; 11.9; 21.3; 25.44; 22.20; 22.38; 35.19; 35.33; Deut. 1.36; 1.38; 20.20; Josh. 11.13; Judg. 7.4; 1 Sam. 14.15; 15.9; 2 Sam. 6.22; 1 Kng. 8.19; 22.14; 2 Kng. 10.29; 17.36.
} 
The dislocated referent "TREES NOT USED FOR FOOD" supplies the missing argument in the presupposed open proposition inferred from v.19: “you may cut down X”. However, the low degree of accessibility entertained by the dislocate triggers the use of a long and complex NP, thus prohibiting the even distribution of a focal accent. By using a Focus Announcing LD, the author is able to mitigate two cognitively costly tasks. The intended referent is activated by

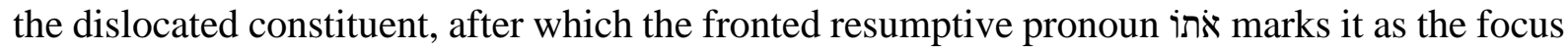
of the open proposition. ${ }^{40}$

\subsection{Framing LD}

A common trait of both Topic and Focus announcing LDs is that the resumptive is co-referential with the dislocate in every instance. However, a third function exists in which this is not the case. Framing LDs accomplish the basic level function of (re)activation, but lack a coreferential resumptive within the core clause. It is sometimes the case that the dislocate is pragmatically related to the following proposition by way of a particular relevance relation. As such, the dislocate functions to restrict the interpretation of the following proposition to a certain semantic domain. The example in (16), from $1 \mathrm{Sam}$. 2.13, is a representative of this type:

$$
1 \text { Sam. } 2.13^{41}
$$

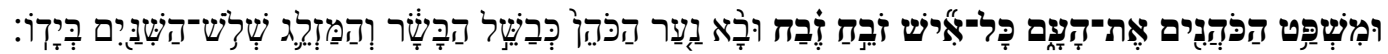
["Now, the custom of the priests], [anyone offering a sacrifice], the priests servant would come while the meat was boiling with a three-pronged fork in his hand."

The LD construction in this example consists of two dislocated NPs, each with a topic framing function. The first dislocate activates a referent that provides a general semantic frame (i.e. priestly customs), that constrains the interpretation of what follows. In turn, the second dislocate, likewise, activates a type identifiable referent that provides a narrower semantic frame within the more general one that precedes (i.e. the event of offering a sacrifice). Both dislocates, then, exhibit a framing function: the first is more general, while the second is more narrow. Together, they function to constrain the interpretation of the following proposition(s) to the relevant domains.

In other tokens, Framing LDs not only constrain the interpretation of what follows, they also establish a pragmatic anchoring relation that facilitates the easy activation of a semantically linked element within the clause. Unlike the previous example, the coherence relation between the dislocate and the linked element within the clause is one of partial identity or metonymy. Moreover, the linked element may function in either a topic or focal relation to the pragmatically structured proposition. For example, consider the instance of LD in Gen. 9.6, represented in example (17):

\footnotetext{
40 Moreover, the particle pִ preceding the dislocate functions to constrain a limiting and countering interpretation of the following proposition (cf. Levinsohn 2011).

${ }^{41}$ Further examples include: Lev. 11.33; 25.32-33: Num. 3:46-47; 34.6; 34.10.
} 
Gen. $9.6^{42}$

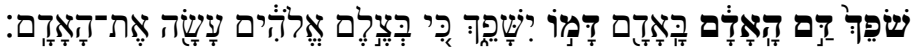

["Whoever sheds the blood of man], by a man shall his blood be shed, for God made man in his own image."

The dislocate and the clause-internal topic expression stand in a metonymic (i.e. a whole-part) relation as a result of the framing function accomplished by the LD construction. In other words, the referent HIS BLOOD is an acceptable topic expression because it is semantically anchored to the newly activated dislocate "WHOEVER SHEDS THE BLOOD OF MAN". ${ }^{43}$

\subsection{Activation of a New Attribute/Profile}

Earlier I observed that some of the dislocates in the dataset exhibit over-encoding. That is, a low accessibility marker is used to encode a referent that is highly accessible. Many of these expressions involve a referential phrase modified by a restrictive relative clause which functions to predicate some new attribute to the referent. The use of LD in such cases derives not from the need to (re)active the referent, but rather, by extension, from the need to activate a new conceptual profile, according to which the referent is recast. A good example of this is found in Gen. 3.12, represented in example (18).

Gen. 3.12

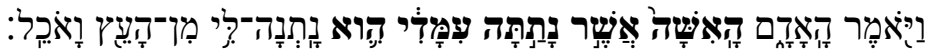
"The man said, ["The woman whom you gave to be with me], she gave me from the tree and I ate."

The referent THE WOMAN has already been established as a salient participate in the discourse and was recently mentioned in v.8. This, along with the fact that the modifying relative clause whom you gave to be with me is semantically non-restrictive, indicates that this referent is highly accessible, despite the highly informative expression used to refer to her. Therefore, a Focus Announcing LD (cf. §4.1.2) is used in this context, not to reactivate the referent, but rather to activate a new conceptual profile. In short, by recasting the woman against this new conceptual profile, the man is able to implicitly implicate Yahweh as the one culpable for his own actions.

\subsection{Less-Prototypical Functions}

The functional profile describe thus far has consisted of constructions that are directly motived by the PSRR. That is to say, that they all involve the (re)activation of a referent, or attribute thereof, that is assumed to entertain a low degree of accessibility. Alternatively, however, some constructions involve the dislocation of referents that entertain a high degree of accessibility. In these cases, expectations associated with the PSRR are exploited in order to disrupt cognitive processing. In other words, where, under prototypical discourse conditions, the use of LD serves to facilitate cognitive-processing, the opposite effect is created in contexts where the processing

\footnotetext{
${ }^{42}$ Further examples include: Gen. 17.15; Exod. 9.6; 26.12; Lev. 11.33; 26.36 (secondary topic); 1 Sam. 3.11.

${ }^{43}$ I interpret the first of the two fronted constituents (i.e. בּאָדָד / "by a man") as a marked focal constituent.
} 
costs are marginal. ${ }^{44}$ Moreover, disruption in processing serves as an ostensive stimulus triggering additional pragmatic implicatures, such as: 1) marking a development shift in the discourse, 2) marking a contrastive/comparative inference, ${ }^{45}$ or 3) foregrounding the associated proposition. Furthermore, these non-prototypical functions represent a more advanced stage on the grammaticalization cline as LD begins to gradually overlap, both formally and functionally, with other construction categories (e.g. fronting).

\subsubsection{Marking a Thematic Shift in the Discourse}

The unexpected dislocation of highly accessible referents is sometimes used to signal a thematic shift in the discourse. This is the case, for example, in Lev. 13.45, represented in (19):

Lev. $13.45^{46}$

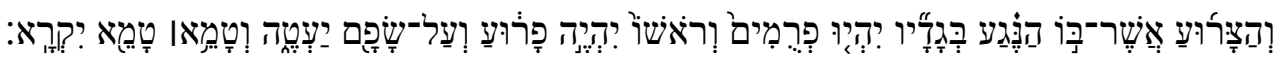
["As for the person inflicted with a skin disease], his clothes shall be torn and his hair shall hang loose, and he shall cover his upper lip and cry out, 'Unclean, unclean'."

Verses 42-44 introduce a person unclean from a grievous skin disease. Because of the referent's active status, there is no need to (re)activate it in v.45. However, the writer chose to use both dislocation and over-encoding, referring to the active participant with a Definite NP modified by a restrictive relative clause: the person who is inflected with a skin disease. This effectively disrupts cognitive processing, thereby signaling a discontinuity in the flow of discourse. Moreover, this discontinuity serves as ostensive stimuli, triggering a specific implicature in this context, namely that a higher level development shift has occurred. In particular, there is a shift from the initial introduction of the diseased person and declaration of their uncleanness, in vv.42-44, to instructions on how they are to behave, in vv.45-46.

\subsubsection{Marking a Comparative/Contrastive Inference}

The over-use of LD may also serve to enhance a contrastive or comparative relation between propositions that would have otherwise been left implicit. The relations of contrast and comparison are typically not encoded by any one lexico-grammatical feature, but are rather

\footnotetext{
${ }^{44}$ In Relevance-Theoretic terms, the hearer does not interpret the (over-)use of LD as cognitively relevant in these contexts since the processing cost required for the construction does not yield sufficient cognitive rewards. This disruption in cognitive processing, in turn, creates an epiphenomenon in which a discontinuity in the discourse is created — one which would not have otherwise been perceived. The reader is therefore forced —in accordance with the relevance-theoretic comprehension procedure-to search for an alternative interpretation that satisfies her expectation of relevance. In other words, assuming the over-use of the construction and resultant discontinuity is a piece of ostensive communication, the reader infers the maximally relevant implicature-i.e. the interpretation that yields the greatest cognitive effects with the least amount of processing effort-in that particular context. These additional pragmatic implicatures include, among others: marking a development shift in the discourse, marking a contrastive/comparative inference, or foregrounding the associated proposition. In light of our distinction between Discourse Function and Discourse Profile, however, it is perhaps more accurate to refer to the following three categories as non-prototypical salient discourse patterns (i.e. profiles; cf. §4.3) that trigger particular pragmatic effects.

${ }^{45}$ Note that in some languages some of this function is more typically accomplished by the fronting construction (cf. Andrason 2016a and 2016be; Khan 2016).

${ }^{46}$ Further examples include: Gen. 48.7; 2 Sam. 13.13.
} 
pragmatically inferred on the basis of contextual assumptions drawn from the content of two or more juxtaposed propositions (cf. Blakemore 2002: 89-148, Vallduvi and Vilkuna 1998). Nevertheless, these implicit relations are often made more explicit by the use of connectives, and word order devices. For instance, a speaker or writer may dislocate a highly accessible/active referent in a particular context in order to pragmatically enhance the otherwise implicit contrast between two entities or propositions. ${ }^{47}$ The over-use of LD in Deut. 18.14b, represented in (20), illustrates this function:

$$
\text { Deut. } 18.14^{48}
$$

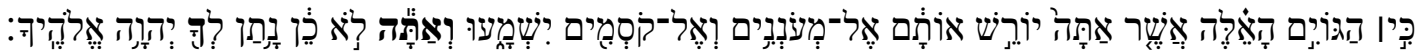
14a: "For these nations which you are about to dispossess listen to those who practice witchcraft and diviners, 14b: [but as for you]i, Yahweh your God has not allowed you to do this."

The contrastive relation between the nations-characterized as those who listen to those who practice witchcraft or divination (v.14a) - and the Israelites, who are prohibited from such activities is contextually inferable from the content and juxtaposition of the two propositions in v.14. Indeed, if one rereads v.14b without the dislocated pronoun, the contrastive relation is still inferable, albeit not as conspicuous. Dislocating the second person plural pronoun you, an expression reserved for active referents, creates a discontinuity in the flow of discourse. This, in turn, has the effect of enriching the implicit contrastive relation between the activities of the nations, and those prohibited by the Israelites.

\subsubsection{Foregrounding Salient Information}

The third non-prototypical function pertains to the over-use of LD as a "foregrounding mechanism" (cf. Heimerdinger 1999: 223-225) used to draw attention to information that the writer considers especially salient in the immediate discourse context. This function derives from the same exploitative processes involved in the over-use of LD to mark thematic shifts or to inflate contrastive/comparative implicatures. In these contexts, however, the unexpected disruption in the flow of discourse functions to pragmatically highlight the propositional information following the dislocated constituent. ${ }^{49}$ This explains the use of LD in Exod. 4.9, represented in (21):

\footnotetext{
${ }^{47}$ It is worth noting that this function (i.e. marking a comparative/contrastive inference) represents a prototypical function of fronting constructions across languages (Erteschik-Shir 2007). Therefore, the fact that LD is also used to accomplish this function, albeit non-prototypically, showcases the advancement of LD along the grammaticalization cline, as it gradually functionally overlaps with fronting. See also Andrason (2016a).

${ }^{48}$ Further examples include: (contrast) Gen. 4.22, 21.13, 22.24, 47.21, Lev. 14.6; (comparison) Gen. 6.21; 17.17; 19.38; 21.13; 22.24; 24.27; 4.22; Lev. 25.44; Deut. 12.22; 28.56; Judg. 11.24; 1 Sam. 13.2.

${ }^{49}$ For additional examples of this function in Neo-Aramaic, see Khan (2016).
} 
"And if they will not believe even these two signs or listen to what you say, you shall take some water from the Nile and pour it on the dry ground; [And the water you take from the Nile], it will become blood on the dry ground."

If the first two signs fail to convince the Israelites and Pharaoh, Yahweh tells Moses to take water from the Nile and pour it on the dry ground. Anticipating that the following proposition will entail a description about what will happen to the water, the reader naturally expects the active referent WATER FROM THE NILE to occur as the pronominally encoded topic expression. Yet, the writer unexpectedly chooses to dislocate and over-encode the active referent, effectively slowing the flow of discourse. ${ }^{51}$ This has the added pragmatic effect of creating a sense of suspense in the reader, thereby highlighting the following proposition

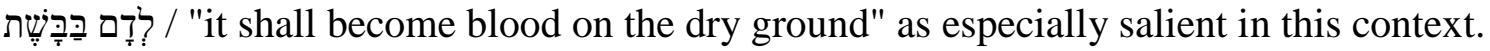

\subsection{Substantive LDs}

Finally, we turn to the functional profile of the three, more substantive, schemas described above (see §2.5ff). The following constructions represent more fixed structural patterns that have, to some degree, conventionalized various aspects of their discourse contexts such that they have come to possess a formulaic use and interpretation. Nevertheless, as we will see, these constructions, for the most part, exhibit the same discourse functions described above, while less often, exhibiting an additional, albeit motivated, discourse function.

\subsubsection{Conditional LDs}

Conditional LDs are primarily used to mark a development shift in the discourse. For example, in Lev. 2.1, represented in (22), the dislocation of the indefinite pronoun נֶֶֶ / "anyone" interrupts the flow of the discourse, thereby marking a thematic shift between "laws pertaining to burnt offerings," in vv. 1:1-17, and "laws pertaining to grain offerings," in vv. 2:1-16.

Lev. $2.1^{52}$

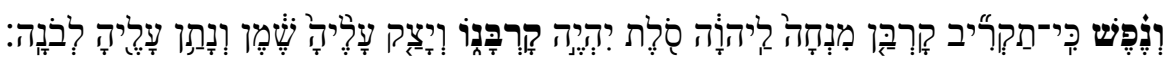
["Anyone], if they bring a grain offering to Yahweh, their offering shall be of fine flour. They shall pour olive oil on it and put frankincense on it."

\footnotetext{
${ }^{50}$ Further examples include: Gen. 21.12; Num. 18.8; 21.8; Judg. 5.3; Josh 23.9, 1 Sam. 20.8.

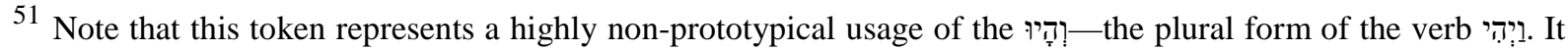
appears as though the first occurrence of this form (i.e. preceding the dislocate) is a case where the verb is used in analogy to the discourse marker lְִ —one that, typically, need not agree in person or number with a subject.

52 Further examples include: Lev. 1.2; 2.1; 4.2; 5.4; 5.15; 5.21; 7.21; 12.2; 13.2; 13.18; 13.24; 13.29; 15.16; 15.19; $15.25 ; 19.20 ; 20.27 ; 22.12 ; 22.13 ; 22.14 ; 22.21 ; 22.27$; Num. 5.6; 5.12-15; 5.20; 6.2; 9.10; 27.8; 30.3; 30.4; 1 Kng. 8.37-39; 9.4.
} 


\subsubsection{Left Dislocation with Anaphoric}

A second type of substantive LD are those constructions characterized by a fronted resumptive adverb כָּ following the dislocated constituent. More than their substantive form, however, these constructions also share a somewhat fixed semantic profile. Consider, for example of Num. 5.4, shown in example (23):

$$
\text { Num. } 5.4^{53}
$$

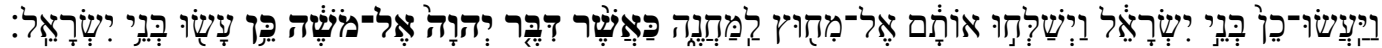
"And the Israelites did so. And they sent them outside the camp. [As Yahweh had instructed Moses]i, soi the Israelites did."

The dislocated PP consists of an accessible proposition that reasserts some, highly generalized, state of affairs that took place between two participants in the previous stretch of discoursee.g. (As) Yahweh instructed Moses. In turn, the core proposition, introduced by a third participant has acted in conformity to the state of affairs activated by the dislocate-e.g. "So the Israelites did".

Moreover, the dislocated PP also has a framing function, not unlike the "Framing LDs" discussed above. (see §4.2). However, the framing relation is one comparison. In other words, the dislocated PP (re)activates accessible information that functions as a comparative frame-as signaled by the adverb

LD constructions with this particular profile prototypically occur at the close of some discourse unit, either a span of reported speech or a narrative scene or episode. The construction is therefore interpreted as a summary statement pertaining to the discourse unit that precedes. It is reasonable to assume that the consistent pairing of this substantive LD with this particular context resulted in a formulaic construction that became a convention in $\mathrm{BH}$ narrative for marking the close of a unite of discourse. ${ }^{54}$

\subsubsection{Temporal LDs}

The final substantive type consists of LD constructions characterized by the dislocation of a temporal expression, marked by a temporal expression of some kind. Moreover, in a majority

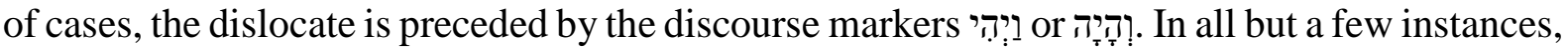
Temporal LDs possess neither a co-referential resumptive nor a semantically linked element within the clause. Nevertheless, in every token, the dislocated constituent is separated from the matrix clause by a clause-initial I (either wayyiqtol, weqatal, or $1+$ fronted XP), thereby confirming its status as an instance of LD. ${ }^{55}$

\footnotetext{
${ }^{53}$ Further examples include: Gen. 6.22; Exod. 7.6; 12.50; 25.9; 27.8; 39.32; 39.42; 39.43; 40.16; Num. 2.17; 2.34; 5.4; 8.4; 8.22; 9.5; 15.14; 17.26; 36.10; Deut. 8.20; Josh. 10.39; 11.15; 14.5; Judg. 1.7; 2 Sam. 7.17; 9.11; 13.35; 16.19; 1 Kng. 1.37; 2.38; 16.11.

${ }^{54}$ Note that in several instances, the construction is followed by the paragraph markers Setuma (0): Exod. 12.28; 12.50; 27.8; 40.16; Num. 2.17; 8.22; 17.26; Or Petukha (פ): Exod. 39.32; 39.43; Num. 5.4; Deut. 8.20; 2 Sam. 16.19 .

${ }^{55}$ By contrast, only three tokens were found that exhibit a resumptive temporal expression within the matrix clause: Exod. 19.1; Num. 9.17a; 2 Sam. 5.24 (cf. §5.4.7.4).
} 
Consistent with its structure (see §2.7), the functional profile of Temporal LDs is highly nonprototypical. In particular, Temporal LDs generally function to mark a discontinuity between mainline events in a narrative by activating a "temporal stage topic"-a temporal expression that specifies or updates the reference time ${ }^{56}$ of a scene or episode (cf. Van der Merwe et al. 1999; Floor 2004). ${ }^{57}$ The updating of the reference time may occur at the onset of a scene or an episode, a development within an episode, or the concluding scene of an episode. For example, in 2 Kng. 4.11, represented in (24), the discontinuity resulting from the dislocated temporal expression signals the onset of a new episode:

$$
2 \text { Kng. } 4.11^{58}
$$

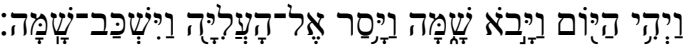

["One day], he came there and turned in to the upper chamber and rested there."

It is also somewhat common in $\mathrm{BH}$ for a temporal expression to occur in a fronted position within the clause, without being detached from it. Fronted temporal expressions are distinguished from dislocated expressions by the lack of an intervening $ו$ between the temporal expression and the matrix clause. Indeed, this typically constitutes the only syntactic difference between the two constructions.

However, the precise functional difference between fronted and dislocated temporal constructions is still in need of further research. Nevertheless, I hypothesized that the LD construction functions to signal a more marked discontinuity in the discourse than its fronted counterpart. Additionally, the Temporal LDs may result from the choice to use a wayyiqtol/weqatal verb form as opposed to qatal/yiqtol in particular contexts. Accordingly, the LD construction would then be a byproduct of the semantic and pragmatic motivations associated with the use a particular verb in context, rather than being motivated by the discourse-pragmatic function of the construction as a whole. However, further research is needed in this regard.

Lastly, the dislocation of temporal expressions also functions as a pragmatic foregrounding device. This generally happens when the content at the end of a proposition is immediately repeated in the form of a dislocated temporal expression at the beginning of the following proposition. The result is a cohesive device referred to in the literature as "Tail-Head Linkage" (cf. Hengeveld and Mackenzie 2008: 3, de Vries 2005, Levinsohn 2000: 200ff). The over-use of LD in these contexts slows down the processing of the discourse, while reinforcing continuity

\footnotetext{
56 "Reference Time refers to that point in time that provides one with a vantage point from which an event is viewed" (Van der Merwe et al. 1999: 94). This is distinguished from "Event Time" (i.e. the time of the event itself), and "Speech Time" (i.e. when reference to an event is made) (ibid.).

${ }^{57}$ In his study on the formal and functional profile of וַיְהי 1 in Samuel, Van der Merwe et al. (1999: 112) writes, "...breaking the wayyiqtol sequence in biblical Hebrew is normally associated with some type of discontinuity between events on the time-line."

${ }^{58}$ Further examples include: Gen. 6.21; 22.21; 27.1; 38.1; 48.1; Josh. 1.1; 5.1; Judg. 1.1; 5.1; 5.13; 9.1; 11.1; 23.1; 24.29; Judg. 1.1; 6.25; 2 Sam. 1.1; 10.1; 15.1; 2 Sam. 11.1; 1 Kng. 9.1; 18.1; 2 Kng. 2.1; 6.24. For tokens that signify a development within an episode, see: Gen. 26.8; 26.32; 30.25; 31.10; 38.24; 38.27; Exod. 16.13; Judg. 3.27; 8.33; 16.4; 1 Sam. 16.6; 18.6; 20.35; 2 Sam. 2.21; 8.1; 11.14; 15.7; 17.21; 21.18; 31.8; 1 Kng. 13.23; 18.36. For those that signify the concluding scene of an episode, see. Gen. 39.7; 40.20; Deut. 31.24; 2 Kng. 19.35.
} 
with what precedes. This has the effect of throwing the subsequent proposition into sharp relief. ${ }^{59}$ A good illustration of this occurs in Gen. 19:16-17:

\author{
Gen. 19:16-17 $17^{60}$
}

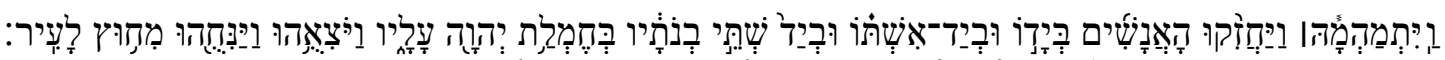

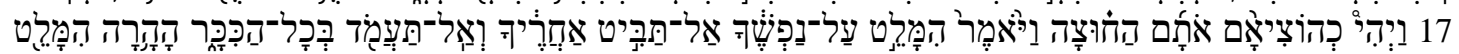

"But he lingered. So the men seized him and his wife and his two daughters by the hand, because of Yahweh's compassion for him; and they brought him out and set him outside the city. 17 [And as they brought them out], one said: Escape for your life! Do not look back or stop anywhere in the valley. Escape to the hills or you will be swept away."

Despite the angel's warning in v.15, Lot resists leaving Sodom, and therefore, he and his family are seized by the visitors and brought outside the city (v.16). The initial dislocate beginning

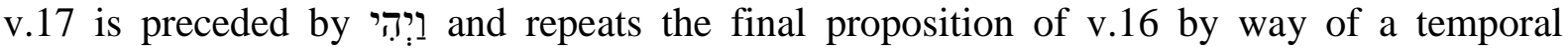
expression headed by כִ. This updates the reference time of the subsequent event as one of immediate temporal proximity with what precedes, while maintaining continuity between the mainline events of the scene. Moreover, the use of tail-head linkage slows down the processing of the discourse which has the effect of foregrounding, or highlighting the following propositional event. In this case, it is the insistent urging by the angel that Lot and his family flee the city at once.

\title{
5. Conclusion
}

By way of conclusion, the functional profile presented here provides a typologically informed explanation of the LD construction in BH. This profile accounts for both the cognitive and contextual motivations for the use of $\mathrm{LD}$ in $\mathrm{BH}$, in addition to the prototypical and less prototypical communicative goals and pragmatic effects achieved by the construction in discourse.

In short, $\mathrm{LD}$ in $\mathrm{BH}$, as in other languages, is iconically motivated by the need to talk about or assert a referent that entertains a low degree of cognitive accessibility. In light of this constraint, it is evident that the construction principally functions as a discursive strategy for (re)activating inaccessible referents, or attributes thereof. These referents may function as the pragmatic topic or focus of the associated proposition, or they may serve as a semantic frame according to which the proposition is understood. Finally, LD may be used in non-prototypical contexts where the dislocate is already highly accessible or even active. In these cases, expectations associated with the prototypical use of LD are exploited in order to disrupt cognitive processing, thereby

\footnotetext{
${ }^{59}$ Van der Merwe, et al. (forthcoming) avers that, in cases where the temporal proximity of two events on the

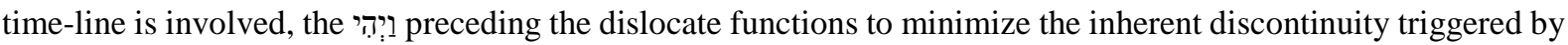
the dislocated temporal expression, thus allowing speakers to "describe the immediate temporal proximity of two events, without breaking the mainstream of events in the scene." Furthermore, these authors note that "these constructions are often used at the climax of a scene in order to signal what triggered a climactic event."

${ }^{60}$ Further examples include: Gen. 24.30; 39.13; 39.15; 39.19; Num. 11.25; Josh. 6.20; Judg. 11.35; 1 Sam. 4.18; 1 Kng. 14.6; 15.21; 16.18; 19.13; 21.16.
} 
triggering additional pragmatic implicatures. Lastly, these non-prototypical functions represent the outer fuzzy edges of the LD category and thus a more advanced stage on the grammaticalization cline, where LD begins to overlap with other constructional categories.

\section{References}

Andrason, A. 2016a. Left Dislocation in Arabic: The complexity of form and meaning. Stellenbosch Papers in Lingusitics Plus 50. 111-138.

Andrason, A. 2016b. To resume or not to resume: Some remarks on 'resumption' in left dislocation constructions in Polish, and its relevance for Biblical Hebrew. Stellenbosch Papers in Lingusitics Plus 50. 185-199.

Ariel, M. 1990. Accessing Noun Phrase Antecedents. London: Routledge.

Ariel, M. 2001. Accessibility Theory: an overview. In T. Sanders, J. Schilperoord, and W. Spooren (Eds.) Text Representation: Linguistic and Psychological Aspects. Amsterdam: John Benjamins. pp. 29-88.

Boas, H. 2013. Cognitive Construction Grammar. In T. Hoffmann, and G. Trousdale (Eds.) The Oxford Handbook of Construction Grammar. Oxford: Oxford University Press. pp. 233-254.

Croft, W.A. and Cruse, A.D. 2004. Cognitive Linguistics. Cambridge: Cambridge University Press.

de Vries, L. 2005. Towards a Typology of Tail-Head Linkage in Papuan Languages. Studies in Language 29(2). pp. 363-384.

Erteschik-Shir, N. 2007. Information Structure: The Syntax-Discourse Interface. Oxford: Oxford University Press.

Evans, V. and Green, M. 2006. Cognitive linguistics: An Introduction. Edinburgh: Edinburgh University Press.

Filmore, C. 1982. Frame Semantics. In The Linguistics Society of Korea (Eds.) Linguistics in The Morning Calm. Soeul: Hanshin. pp. 111-138.

Floor, S. 2004. From Information Structure, Topic and Focus, to Theme in Biblical Hebrew Narrative. PhD dissertation. University of Stellenbosch.

Givon, T. 1983. Topic Continuity in Discourse: A Quantitative Cross-language Study. Amsterdam: John Benjamins Publishing Company.

Givoń, T. 2001. Syntax: An introduction. (2nd Vols). Amsterdam: John Benjamins Publishing Company.

Goldberg, A. 2013. Constructionist Approaches. In T. Hoffmann and G. Trousdale (Eds.) Oxford Handbook of Construction Grammar. Oxford: Oxford University Press. pp. 15-31. 
Gross, W. 1987. Die Pendenskonstruktion im biblischen Hebräisch. St. Otillien: EOS.

Gundel, J.K., Hedberg, N. and Zacharski, R. 1993. Cognitive Status and the Form of Referring Expressions in Discourse. Language 69(2). 274-307.

Heimerdinger, J.-M. 1999. Topic, Focus and Foreground in Ancient Hebrew Narratives. Sheffield: Sheffield Academic Press.

Hengeveld, K. and Mackenzie, L.J. 2008. Functional Discourse Grammar: A Typologicallybased Theory of Language Structure. Oxford: Oxford University Press.

Hoffmann, T. and Trousdale, G. (Eds.) 2013. The Oxford Handbook of Construction Grammar. Oxford: Oxford University Press.

Khan, G. 1988. Studies in Semitic Syntax. Oxford: Oxford University Press.

Khan, G. 2016. Left Dislocation in North-Eastern Neo-Aramaic Dialects. Stellenbosch Papers in Lingusitics Plus 50. 91-110.

Lakoff, G. 1987. Women, Fire, and Dangerous Things: What Categories Reveal about the Mind. Chicago: University of Chicago Press.

Lambrecht, K. 1994. Information Structure and Sentence Form: Topic, focus, and the Mental Representations of Discourse Referents. Cambridge: Cambridge University Press.

Lambrecht, K. 2001. Dislocation. In M. Haspelmath, E. Konig, W. Oesterreicher, and W. Raible (Eds.) Typology and Language Universals. Berlin: Walter de Gruyter. pp. 1050-1078.

Levinsohn, S. 2000. Discourse Features of New Testament Greek. Summer Institute of Linguistics.

Lopez, L. forthcoming. Dislocations. in C. Féry and S. Ishihara (Eds.) Oxford Handbook of Information Structure. Oxford: Oxford University Press.

Naudé, J. 1990. A Syntactic Analysis of Dislocations in Biblical Hebrew. Journal of Northwest Semitic Language 16. 115-130.

Nikolaeva, I. 2001. Secondary topic as a relation in information structure. Linguistics 39(1). 149.

Prince, E. 1981. Toward a Taxonomy of Given-New Information. In Cole, P. (Ed.) Radical Pragmatics. New York: Academic Press. pp. 223-255.

Taylor, J.R. 1995. Linguistic Categorization: Prototypes in Linguistic Theory. Oxford: Oxford University Press.

Tizon-Couto, D. 2012. Left Dislocation in English: A Functional-Discoursal approach. Switzerland: Peter Lang AG, Internationaler Verlag der Wissenschaften. 
Van der Merwe, C.H.J., Kroeze, J. and Naudé, J. 1999. Biblical Hebrew Reference Grammar. Sheffield: Sheffield Academic Press.

Van der Merwe, C.H.J., Kroeze, J. and Naudé, J. forthcoming. Biblical Hebrew Reference Grammar. London: Bloomsbury.

Villalba, X. 2000. The Syntax of Sentence Periphery. PhD dissertation, Universitat Autònoma de Barcelona.

Westbury, J. 2014. Left Dislocation in Biblical Hebrew: A Cognitive Linguistic Account. PhD dissertation, University of Stellenbosch.

Westbury, J. 2016. Left Dislocation: a typological overview. Stellenbosch Papers in Linguistics Plus 50. 21-45. 